\title{
CLINICAL EXPERIENCE WITH A FIXED DOSE COMBINATION THERAPY OF TIMOLOL AND PILOCARPINE USED TWICE DAILY IN THE MANAGEMENT OF CHRONIC OPEN ANGLE GLAUCOMA
}

\author{
A. P. MORIARTY, T. C. DOWD and R. B. TRIMBLE \\ Liverpool
}

\begin{abstract}
SUMMARY
Twenty-five eyes of 25 patients with primary chronic open angle glaucoma deemed controlled for 12 months were converted from timolol $0.25 \%$ or $0.5 \%$ b.d. and pilocarpine $2 \%$ q.i.d. to a combination drop $\left(\mathrm{TP}_{2}\right)$ of combined timolol $0.5 \%$ and pilocarpine $2 \%$ given b.d. Mean intraocular pressures (IOP) were $18.68 \pm 2.84 \mathrm{mmHg}$ at 1 month, $18.81 \pm 2.56 \mathrm{mmHg}$ at 3 months and $18.56 \pm 2.01 \mathrm{mmHg}$ at 6 months. These values were significantly higher than the initial IOP of $17.48 \pm 2.2 \mathrm{mmHg}$ ( $p$ values $0.0006,0.0001$ and 0.0004 respectively). However, 1 month following reconversion to initial therapy the IOP was $17.68 \pm 2.67 \mathrm{mmHg}$, which was not significantly higher than the initial IOP $(p=0.46)$. In addition, of 8 eyes uncontrolled during the course of the study, 6 became controlled following reconversion to initial treatment. Combination therapy of $\mathbf{T P}_{2}$ b.d. cannot be recommended to control IOP satisfactorily in patients maintained on timolol $0.25 \%$ or $0.5 \%$ b.d. and pilocarpine $2 \%$ q.i.d.
\end{abstract}

Topical beta blockers are the most commonly used ocular hypotensive agents. Between $10 \%$ and $30 \%$ of patients may require additional therapy, however, ${ }^{1-3}$ and the most frequently used ad junct is topical pilocarpine. In $50 \%$ of cases control will be regained and this synergy of action may be due to differing modes of action of the two drugs. ${ }^{4.5}$ Pilocarpine requires a four times daily (q.i.d.) treatment schedule to achieve a consistent effect, ${ }^{6,7}$ compared with the twice-daily (b.d.) schedule for topical beta blockers. Compliance with glaucoma medication is adversely influenced by increasing complexity of treatment regime. ${ }^{8}$ Twentyfour hour diurnal studies by Maclure and Vogel ${ }^{9}$ suggest that the additive effect of pilocarpine on timolol is main-

From: St Paul's Eye Hospital, Liverpool, UK.

Correspondence to: Mr A. P. Moriarty, MA, FRCS, FRCOphth. Senior Registrar, Department of Ophthalmology, Royal Perth Hospital. Wellington Street, Perth, Western Australia 6000. tained by pilocarpine b.d. as effectively as a q.i.d. dosage. Other workers have shown that the hypotensive action of pilocarpine lasts for at least 12 hours when used as a fixed dose combination with $0.5 \%$ timolol. ${ }^{10}$ It appears that combination with timolol produces synergy which extends the action of pilocarpine. Theoretically this should allow the use of a b.d. combined preparation of timolol and pilocarpine to achieve an additional hypotensive effect while maintaining compliance.

This prospective study was undertaken to test the hypothesis that a combined preparation of timolol $0.5 \%$ and pilocarpine $2 \%$, when used on a b.d. basis, produces satisfactory control of IOP in patients with open angle glaucoma over a 6-month trial period.

\section{MATERIALS AND METHODS}

\section{Patients}

Thirty patients with primary chronic open angle glaucoma (COAG) were recruited from the Glaucoma Clinic of St Paul's Eye Hospital, Liverpool.

\section{Inclusion and Exclusion Criteria}

The inclusion criteria were stable glaucoma over the preceding 12 months using both topical timolol $(0.25 \%$ or $0.5 \%$ ) b.d. and topical pilocarpine $2 \%$ q.i.d. such that IOP had been controlled at or below $21 \mathrm{mmHg}$ with noevidence of continuing visual field loss or optic disc deterioration.

The general exclusion criteria were asthma, chronic obstructive airways disease, cardiac failure or dysrhythmia. The ocular exclusion criteria were acute ocular infection, previous uveitis, intraocular surgery, herpes simplex keratitis, corneal ulceration, contact lens wear, or any corneal abnormality which might affect accurate applanation tonometry or drug penetration kinetics.

\section{Pre-trial Assessment}

After initial identification and recruitment of patients, all 
were assessed three times during the 3-week pre-trial period to determine baseline IOP values while using their accustomed medication. In this period patients were asked to use their usual treatment at $0800,1200,1600$ and 2000 hours.

Examinations were then conducted at 1000 hours comprising visual acuity, pupil size, Goldmann three-minor gonioscopy, Goldmann applanation tonometry and funduscopy to assess the optic disc appearance. (The nature of the study made it impossible to perform masked measurements of IOP but in all instances applanation was performed three times by one observer, without reference to the tonometry reading, which was recorded by an independent witness to eliminate observer bias.) The mean of the three readings was then calculated. On the first of the three visits Friedman mark II static visual fields were analysed. Heart rate and blood pressure were measured and any systemic or ocular symptoms noted. At the end of the 3 -week period 2 patients were deemed not to fulfil the criteria for controlled glaucoma and did not continue into the trial. Three patients failed to complete the full study period and are therefore not included.

\section{Trial Schedule}

The 25 patients who successfully completed the pre-trial assessment and follow-up were switched from their previous separate timolol and pilocarpine $2 \%$ to the combined b.d. timolol/pilocarpine preparation $\left(\mathrm{TP}_{2}\right)$. These combinationdrops were reconstituted by the pharmacy staff of the Eye Hospital as described elsewhere ${ }^{11}$ and were prescribed for instillation at 0800 and 2000 hours. Each bottle was used for 21 days before being discarded and a fresh one dispensed.

The patients were then examined at 1, 3 and 6 months with the same measurements as at the pre-trial visits; Friedman visual fields were tested on each occasion. In the event of IOP exceeding $21 \mathrm{mmHg}$ at 1000 hours ( 2 hours after instillation of combined dosage preparation) or any deterioration in field or optic disc, patients using the $\mathrm{TP}_{2}$ preparation were withdrawn from the trial and returned to their previous medication and the Glaucoma Clinic for further management as judged clinically appropriate, and reassessed at 1 month following conversion back to original therapy.

For the purposes of statistical analysis, those patients who had both eyes treated had only one eye randomised into inclusion into the trial. ${ }^{12}$ Patients withdrawn from the trial because of lack of control were excluded from further statistical analysis.
At the end of the 6-month trial period all patients remaining in the trial returned to their initial therapy and supervision and were assessed at 1 month following reconversion. All patients had access to the investigators during the period of the trial and replacement therapy from the pharmacy staff at St Paul's. Informed consent was obtained from each patient and the trial received Ethics Committee approval.

\section{RESULTS}

Of 30 patients initially recruited only 28 were deemed eligible for inclusion in the study after a 3-week initial study period. Three further patients did not complete all follow-up visits and therefore a total of 25 patients ( 25 eyes) entered and completed the study period. All had IOPs at 1000 hours $\leqslant 21 \mathrm{mmHg}$ after instillation of usual timolol $(0.25 \%$ or $0.5 \%)$ and pilocarpine $(2 \%)$ at 0800 hours.

There were 13 men and 12 women with an age range of 54-81 years (mean 70.96 years). Control of IOP was defined as IOP $\leqslant 21 \mathrm{mmHg}$ at 1000 hours. Mean IOPs in eyes prior to conversion, at 1, 3 and 6 months after conversion to combination therapy, and at 1 month after reconversion to initial therapy are shown in Table I and graphically in Fig. 1. Table II and Fig. 2 demonstrate the percentage of eyes controlled by combination therapy at the same intervals.

Twenty-five eyes of 25 patients were included in the trial and deemed controlled initially. During the course of the trial only 17 eyes were controlled at 6 months. Of those 8 uncontrolled eyes, 6 regained control by conversion to original therapy whilst 2 required control by argon laser trabeculoplasty.

\section{Statistical Analysis}

Statistical analysis was by a paired Student's $t$-test. Comparison of the mean IOP at 1 month $(18.68 \pm 2.84 \mathrm{mmHg}), 3$ months $(18.81 \pm 2.56 \mathrm{mmHg})$ and 6 months $(18.56 \pm 2.06 \mathrm{mmHg})$ compared with the mean IOP at initiation (17.48 $\pm 2.22 \mathrm{mmHg}$ ) showed that IOPs were statistically higher than baseline values $(p$ values $0.0006,0.0001$ and 0.0004 respectively). One month following reconversion to original therapy in the 25 eyes there was no significant elevation in IOP $(17.68 \pm 2.67, p$ value 0.46$)$ compared with baseline values $(t 0)$.

\section{DISCUSSION}

Previous studies have suggested that control of IOP may be possible when pilocarpine $2 \%$ or $4 \%$ b.d. rather than q.i.d.is added to timolol $0.5 \%$ b.d. ${ }^{9}$ Encouraged by this a combi-

Table I. Mean intraocular pressures $(\mathrm{mmHg})$

\begin{tabular}{|c|c|c|c|c|c|}
\hline $\mathrm{n}=$ & $\begin{array}{c}t 0 \\
(n=25)\end{array}$ & $\begin{array}{l}1 \text { month } \\
(n=25)\end{array}$ & $\begin{array}{l}3 \text { months } \\
(n=21)\end{array}$ & $\begin{array}{l}6 \text { months } \\
(n=18)\end{array}$ & $\begin{array}{l}1 \text { month after reconversion } \\
\qquad(n=25)\end{array}$ \\
\hline $\begin{array}{l}\text { Mean } \\
(\mathrm{SD}) \\
p \text { value }^{\mathrm{a}}\end{array}$ & $\begin{array}{c}17.48 \\
( \pm 2.22)\end{array}$ & $\begin{array}{c}18.68 \\
( \pm 2.84) \\
0.0006\end{array}$ & $\begin{array}{c}18.81 \\
( \pm 2.56) \\
0.0001\end{array}$ & $\begin{array}{c}18.56 \\
( \pm 2.06) \\
0.0004\end{array}$ & $\begin{array}{c}17.68 \\
( \pm 2.67) \\
0.46\end{array}$ \\
\hline
\end{tabular}

The mean age of the patients was $70.96 \pm 5.98$ years.

${ }^{\mathrm{a}}$ Compared with $t 0$ 


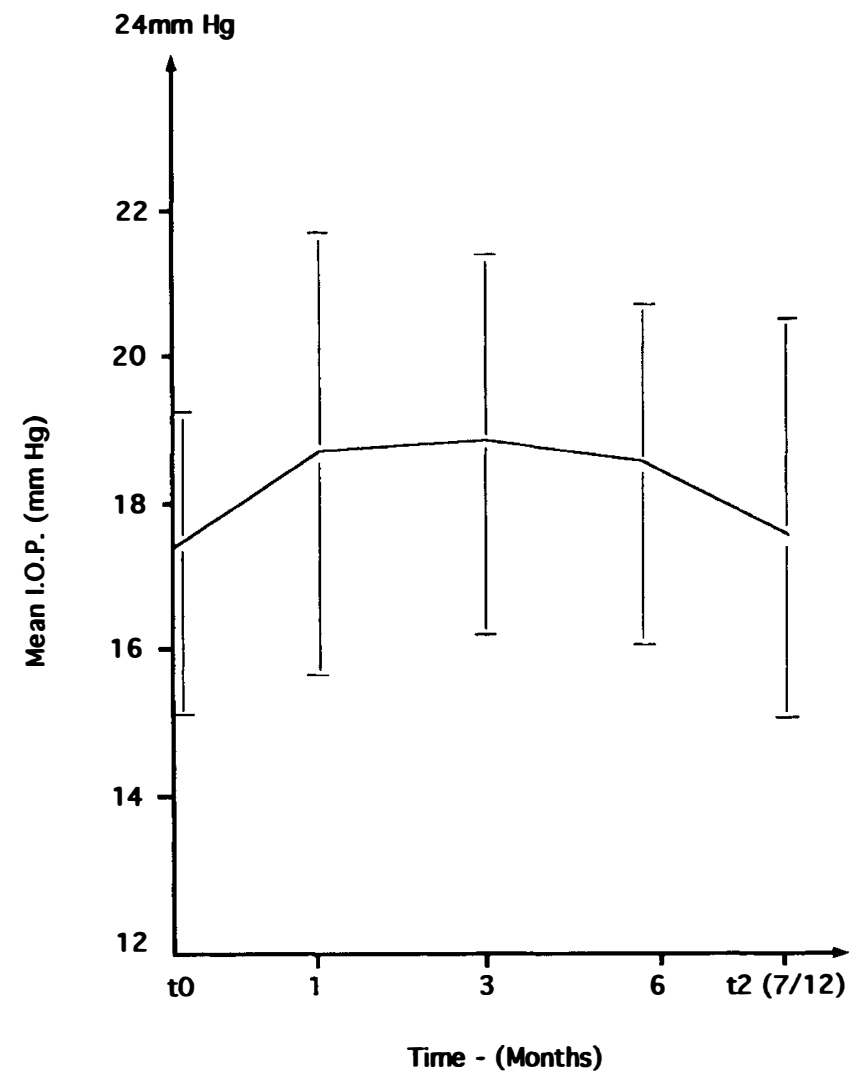

Fig. 1. Mean intraocular pressures $(I O P, m m H g)$ prior to conversion to combination therapy ( $\mathrm{t} 0)$, and at 1,3 and 6 months on combination therapy. $\mathrm{t} 2$ is the mean IOP at 1 month following reconversion to initial therapy.

nation therapy of timolol $0.5 \%$ and pilocarpine $2 \%\left(\mathrm{TP}_{2}\right)$ or pilocarpine $4 \%\left(\mathrm{TP}_{4}\right)$ was compared with either timolol $0.5 \%$ b.d. or pilocarpine $4 \%$ q.i.d. in patients with morning IOPs $>21 \mathrm{mmHg}$. Combination treatment controlled IOP in a significant number of patients where timolol $0.5 \%$ alone or pilocarpine $4 \%$ alone had not. ${ }^{13}$ Lack of sideeffects and patient acceptability led to a number of trials comparing the fixed dose combination used b.d. with conventional timolol and pilocarpine given separately in the more accepted dose regimes. Combination therapy $\mathrm{TP}_{2}$ or $\mathrm{TP}_{4}$ (b.d.) had a significant lowering effect on IOP when compared with pilocarpine $4 \%$ q.i.d. ${ }^{15,16}$ and when compared with timolol $0.5 \%$ b.d. ${ }^{13,14}$ These studies, however, were over short periods of 8 weeks maximum, though a recent study over 48 weeks drew similar conclusions. ${ }^{17}$

In the fixed dose combinations the additive effect of pilocarpine was said to last at least 12 hours when used in combination with timolol. Other studies have reached similar conclusions. ${ }^{18,19}$ The 12 hour IOP control by application of $\mathrm{TP}_{2}$ or $\mathrm{TP}_{4}$ was improved when compared with timolol $0.5 \%$. In addition reduced mean diurnal IOP and reduced

Table II. Eyes controlled (IOP $\leqslant 21 \mathrm{mmHg}$ )

\begin{tabular}{lll}
\hline$t$ & 25 & \\
1 month & 21 & $(86 \%)$ \\
3 months & 18 & $(72 \%)$ \\
6 months & 17 & $(68 \%)$ \\
1 month after reconversion & 23 & $(92 \%)$ \\
\hline
\end{tabular}

frequency of large pressure peaks were also recorded..$^{10,14}$ However, these findings are not surprising since the addition of another medication whether separately or as combination therapy would be expected to control IOP more effectively than a single medication.

The real comparison is when combination treatment of $\mathrm{TP}_{2}$ or $\mathrm{TP}_{4}$ is compared with a regime of both timolol and pilocarpine separately. Indeed two studies suggested that fixed ratio combination treatment of $\mathrm{TP}_{2}$ or $\mathrm{TP}_{4}$ (b.d.) was as effective in controlling IOP as timolol (b.d.) and pilocarpine (t.i.d.) given separately. ${ }^{20.21}$ However, in these studies there was a loose regime of pilocarpine instillation, the studies were of 4 weeks duration and IOP was measured at 0800 hours prior to instillation of the next treatment dose.

One would expect that in view of all these findings $s^{9,10,20,21}$ combination therapy would be as effective as timolol b.d. and pilocarpine b.d. or t.i.d. given separately. Given that pilocarpine's effect is prolonged to at least 12 hours with concomitant timolol ${ }^{12,15}$ then combination therapy should be as effective as timolol b.d. and pilocarpine q.i.d. given separately.

Our study was, therefore, specifically designed to mimic the clinical situation in which patients previously controlled on timolol b.d. and pilocarpine $2 \%$ q.i.d. in a pre-study period were converted to $\mathrm{TP}_{2}$ (b.d.). The IOPs were measured at a specific time ( 1000 hours) after instillation of the morning dose ( 0800 hours) in both the pre-study and the study period. This was to reflect clinic management more closely.

We were disappointed to discover that in a long period of follow-up (6 months) only 17 of 25 eyes (68\%) were controlled. Of those 8 eyes uncontrolled on combination therapy, 6 eyes became controlled on reversion to the original therapy, whilst 2 eyes did not.

The results of our study were at variance with the findings of previous studies, in particular with those comparing timolol b.d. and pilocarpine t.i.d. with a fixed dose combination. ${ }^{20.21}$ However, our patients were previously on pilocarpine q.i.d. and the possibility remains that the b.d. combination might be effective in controlling patients whose IOPs were satisfactorily controlled with pilocarpine t.i.d. and timolol b.d. but not effective when compared with

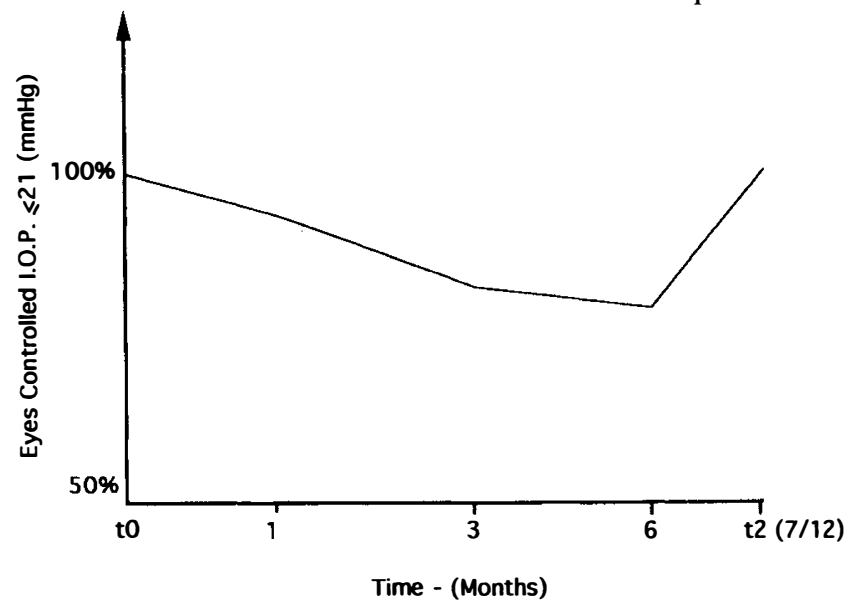

Fig. 2. Percentage of eyes controlled at $\mathrm{t} 0$, at 1,3 and 6 months following conversion to combination therapy and at $\mathrm{t} 2$ (1 month following reconversion to initial therapy). 
pilocarpine q.i.d. and timolol b.d. However, from kinetic studies there is really little difference between the control exerted by pilocarpine t.i.d. and pilocarpine q.i.d. ${ }^{9} .10,12.18 .19$ Perhaps the fact that IOP was measured 2 hours after dosage instillation, unlike the pre-dose IOP measurements in other studies, was significant. ${ }^{15.16 .18}{ }^{21}$ However, this was the same protocol for the pre-study period when patients were maintained and controlled on the previous therapy. Our study period was considerably longer ( 6 months) than that of most other similar studies of combination therapy (4-8 weeks) and perhaps this was significant.

Progression of the disease process or tachyphylaxis may have been responsible for loss of control, though reversion to original therapy seemed to allow control in some patients and to be associated with a significant reduction in IOP in these patients. Non-compliance may have been a reason for failure, though miosis suggested patients were compliant and a b.d. regime would be more likely to encourage compliance.

The major variable lies in drug administration and kinetics. Timolol maleate has a $\mathrm{pH}$ of 7 , but at this $\mathrm{pH}$ pilocarpine is unstable and pilocarpine is usually used in solutions of $\mathrm{pH} 5.5{ }^{13.21}$ In the combination used the $\mathrm{pH}$ was about 6.6 , and though it converts more rapidly to pilocarpine acid and iso-pilocarpine acid it is probably stable for 3 weeks. ${ }^{22.23}$ However, this is a possible source of error since the pilocarpine in combination therapy may be more unstable $^{22}$ than when used in acid solution as a single therapy, leading to inactivation of the pilocarpine element of the fixed dose combination. This might lead to a relative inefficacy of combination therapy compared with a separate treatment regime and explain our disappointing results. However, the higher $\mathrm{pH}$ encourages conversion to pilocarpine acid and iso-pilocarpine and the greater concentrations of an ionised drug promote penetration of the corne $\mathrm{a}^{2+}$ and a greater hypotensive effect at $\mathrm{pH} 6.6$ compared with lower $\mathrm{pH}$ values. ${ }^{25}$

Our trial can be criticised in that it was an open label study with no control group. However, the patients did act as 'their own controls' in that they had been studied in a prestudy period before entering the trial. Indeed the aim of our study was to mimic the clinical situation as closely as possible with the combination treatment.

Although patient acceptibility was high, we feel that our experience with a fixed dose combination of timolol and pilocarpine $\left(\mathrm{TP}_{2}\right)$ used b.d. does not allow us to recommend it for use in patients controlled on timolol b.d. and pilocarpine $2 \%$ q.i.d.

Key words: Combination therapy. Glaucoma, Pilocarpine. Timolol.

\section{REFERENCES}

1. Luke-Long L, Galin MA. Obstbaum SA. Long term timolol therapy. Surv Ophthalmol 1979:23:377-80.

2. Rosenbaum LJ. A controlled clinical evaluation of timolol in the treatment of patients with elevated intraocular pressure. Glaucoma 1979;1:21-4.

3. Krupin T, Singer P, Perlmutter J, et al. One hour intraocular pressure response to timolol: lack of correlation with long term response. Arch Ophthalmol 1981:99:840-1.
4. Coakes RL, Brubaker RF. The mechanism of timolol in lowering the IOP in the normal eye. Arch Ophthalmol 1978:96:2045.

5. Ashburn FS, Gillespie JE, Kass MA, et al. Loss of acute pilocarpine effect on outflow facility following surgical disinsertion and retrodisplacement of the ciliary muscle from the scleral spur in the Cynomolgus monkey. Invest Ophthalmol Vis Sci 1976;15:793.

6. Ellis P. Ocular therapeutics and pharmacology. 5th ed. St. Louis: C. V. Mosby, 1977:128-9.

7. Hass I, Drance SM. Comparison between pilocarpine and timolol on diurnal pressure in open angle glaucoma. Arch Ophthalmol 1980;98:480-1.

8. Granstrom PA. Glaucoma patients not compliant with their drug therapy: clinical and behavioural aspects. Br J Ophthalmol 1982;66:464.

9. Maclure GM. Vogel R. The effect on diurnal control of IOP of co-administration of pilocarpine and timolol. New Trends Ophthalmol 1987;II:79-86.

10. Lofors KT, Hovding G, Viksmoen L, et al. Twelve hour IOP control obtained by a single dose of timolol/pilocarpine combination eye drops. Acta Ophthalmol (Copenh) 1990;68:332-6.

11. Hovding G, Ausved H. Timolol/pilocarpine combination eye drops in open angle glaucoma and in ocular hypertension. Acta Ophthalmol (Copenh) 1987;65:594-601.

12. Katz J. Two eyes or one? The data analysis dilemma. Ophthalmic Surg 1988; 19:585-9.

13. Vogel R. Overview of efficacy and local tolerability of a new timolol/pilocarpine combination. Surv Ophthalmol 1989;33(Suppl):467-8.

14. Maclure GM, Vogel R, Sturm A, Binkowitz B. Effect on the 24 hour diurnal curve of intraocular pressure of a fixed ratio combination of timolol $0.5 \%$ and pilocarpine $2 \%$ in patients with COAG not controlled on timolol $0.5 \%$. Br J Ophthalmol 1989; 73:827-31.

15. Thygesen J. Comparison of timolol and pilocarpine combination versus pilocarpine alone in the management of glaucoma: a randomised double masked study. Chibret Int $\mathbf{J}$ Ophthalmol 1990;7:57-62.

16. Airaksinen PJ, Valkonen R, Stenborg T, et al. A double masked study of timolol and pilocarpine combined. Am J Ophthalmol 1987:104:587-90.

17. Puustjarvi TJ, Pepo LP. Timolol-pilocarpine fixed ratio combinations in the treatment of chronic open angle glaucoma: a controlled multicentre study of 48 weeks. Arch Ophthalmol 1992;110:1725-9.

18. Hovding G. fixed ratio timolol and pilocarpine combination in the management of open angle glaucoma: Scandinavian multicentre study. Chibret Int J Ophthalmol 1990;7:63-7.

19. Puustjarvi T, Aine E, Hakala T. The effect of two timolol and pilocarpine combinations versus timolol $0.5 \%$ in the treatment of open angle glaucoma. Chibret Int $\mathrm{J}$ Ophthalmol 1990;7:68-71.

20. Thorburn W. Comparison of timolol and pilocarpine combination versus concomitant therapy with separate components: a Swedish multicentre study. Chibret Int J Ophthalmol 1990;7:50-3.

21. Soderstrom MB, Wallin O, Granstrom PA, Thorburn W. Timolol-pilocarpine combined versus timolol and pilocarpine given separately. Am J Ophthalmol 1989;107:465-70.

22. Chung PH, Chin TF, Lach JL. Kinetics of the hydrolysis of pilocarpine in aqueous solution. $J$ Pharm Sci 1970;59:1300-6.

23. Merck, Sharp \& Dohme. Personal communication, 1987.

24. Ramer RM, Gasett AR. Ocular penetration of pilocarpine. Ann Ophthalmol 1975;7:293.

25. Anderson RA, Cowle JB. Influence of $\mathrm{pH}$ on the effect of pilocarpine on aqueous dynamics. $\mathrm{Br} \mathrm{J}$ Ophthalmol 1968;52:607. 